\title{
3D Foot Scanning System INFOOT - Automated Anatomical Landmark Detection and Labeling
}

\author{
Kozo KIMURA ${ }^{\mathrm{a}}$, Tsuneaki UTSUMI ${ }^{\mathrm{a}}$, Makiko KOUCHI ${ }^{\mathrm{b}}$, Masaaki MOCHIMARU ${ }^{\mathrm{b}}$ \\ a I-Ware Laboratory Co. Ltd, Osaka ,Japan; \\ ${ }^{\mathrm{b}}$ Digital Human Research Center, AIST, Tokyo, Japan
}

\section{Introduction}

INFOOT was developed out of a collaboration between I-Ware Laboratory Co.,Ltd (hereafter IWL) and Digital Human Research Center(hereafter DHRC). INFOOT is a 3D foot scanning system which obtains 3 dimensional foot shape data and landmark positions to calculate foot dimensions automatically. INFOOT has been used for research purposes and, more recently, used for shoe selection and customized shoe manufacturing.

\section{Scanning method}

INFOOT is an optical laser scanning system which consists of 4 laser projectors and 8 CCD cameras which capture a projected line on the foot surface. The system provides $0.5 / 1.0 \mathrm{~mm}$ scan pitch and 30 $\mathrm{mm} / \mathrm{sec}$ scan speed. It can detect $5 \mathrm{~mm}$ diameter marker dots placed on landmarks, obtain their 3D coordinate and label their anatomical names based on a probabilistic database. These processes can all be achieved and completed during the scanning process (Fig. 1).

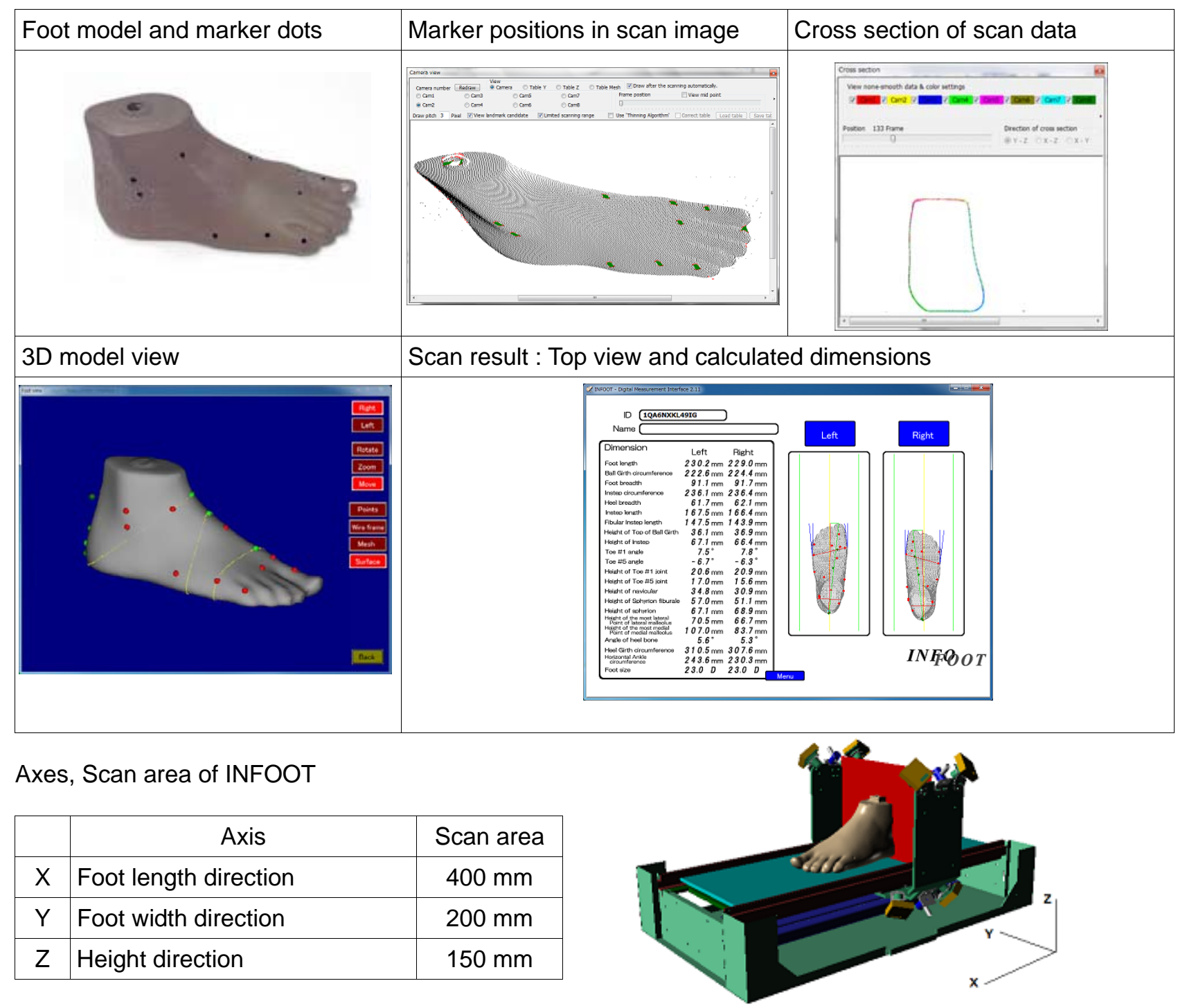

Fig. 1. Marker dots, scanning volume, and measured results by an INFOOT system. 


\section{Definition of measurement}

Foot measurements are defined by M. Kouchi and M. Mochimaru according to the definitions by Martin and Knussmann [1], as well as demands from the shoe industry, orthopedists and biomechanists as shown in Fig. 2 below.

\begin{tabular}{|r|l|}
\hline \multicolumn{2}{|c|}{ Measuring items } \\
\hline 0 & Foot length \\
\hline 1 & Ball Girth circumference \\
\hline 2 & Foot breadth \\
\hline 3 & Instep circumference \\
\hline 4 & Heel breadth \\
\hline 5 & Instep length \\
\hline 6 & Fibulare Instep length \\
\hline 7 & Height of Top of Ball Girth \\
\hline 8 & Height of Instep (Default: $50 \%$ of foot length) \\
\hline 9 & Toe \#1 angle \\
\hline 10 & Toe \#5 angle \\
\hline 11 & Toe \#1 height \\
\hline 12 & Toe \#5 height \\
\hline 13 & Height of Navicular \\
\hline 14 & Height of Sphyrion fibulare \\
\hline 15 & Height of Sphyrion \\
\hline 16 & Height of the most lateral point of lateral malleolus \\
\hline 17 & Height of The most medial point of medial malleolus \\
\hline 18 & Arch length \\
\hline 19 & Angle of heel bone \\
\hline 20 & Heel Girth circumference \\
\hline 21 & Horizontal Ankle circumference \\
\hline 22 & Calf Circumference(height 230mm) \\
\hline & \\
\hline
\end{tabular}
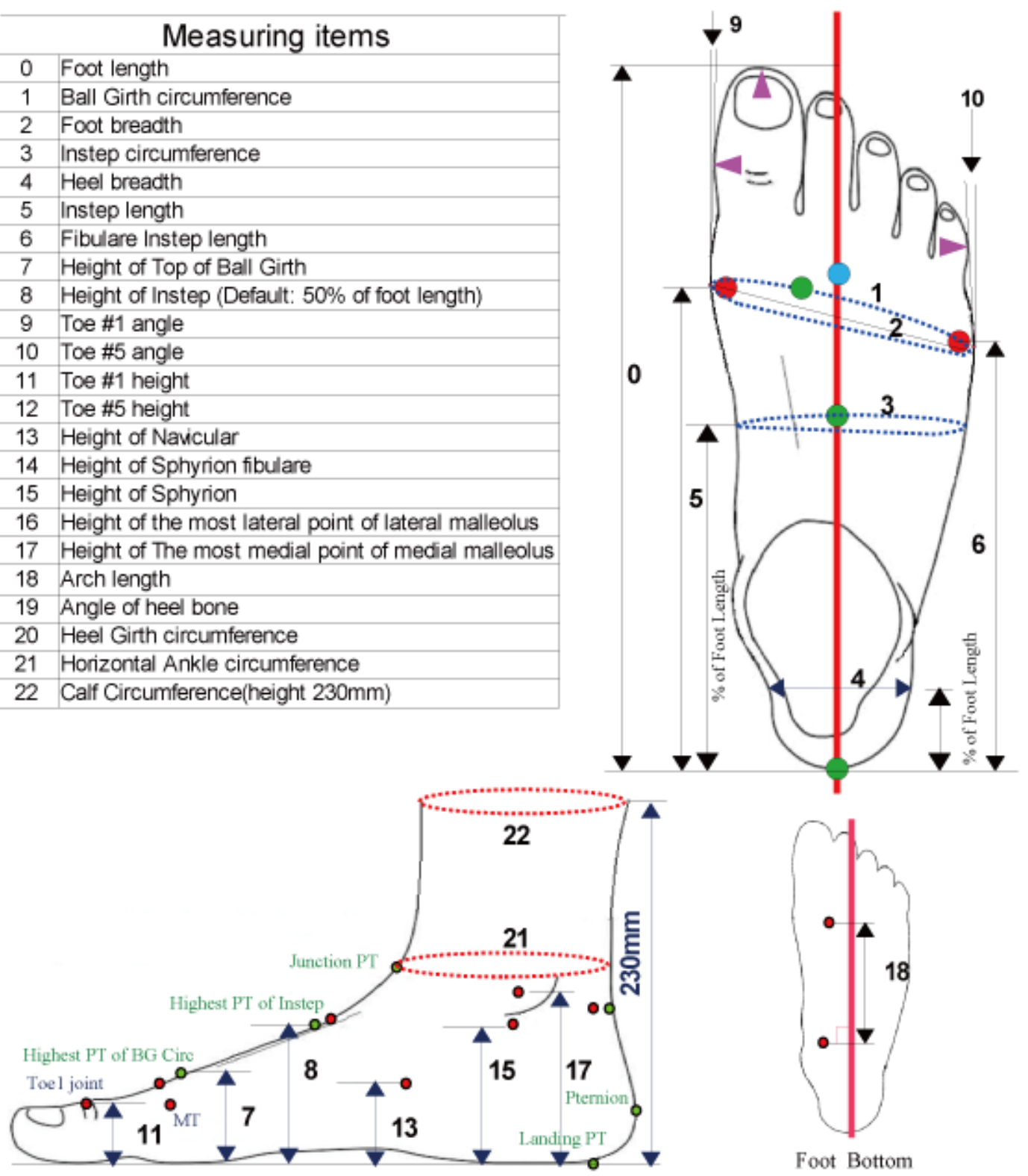

Foot Bottom
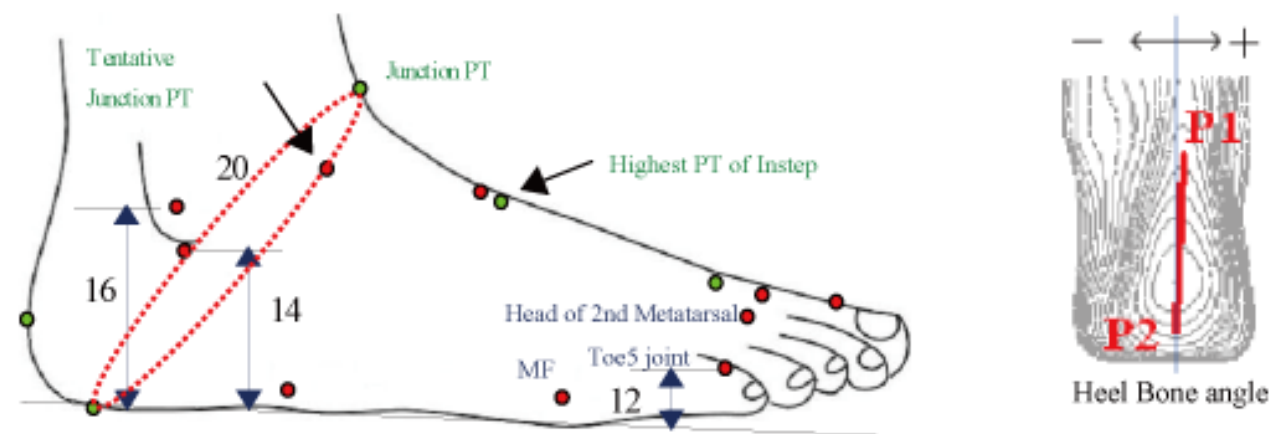

Heel Bone angle

Fig. 2. Foot dimensions obtained by an INFOOT system 


\section{Applications}

Foot data scanned by INFOOT is used for analysis/evaluation of an individual foot, morphological and dimensional foot statistics, shoe design, shoe selection and shoe and insole customization for local shop/clinical use, as well as via networks as follows:

\begin{tabular}{|l|l|l|}
\hline \multicolumn{1}{|c|}{ Purpose } & \multicolumn{1}{c|}{ User/Supplier } & \multicolumn{1}{c|}{ Application } \\
\hline Foot evaluation & Shoe maker & Dimension-based foot evaluation \\
\hline Foot analysis & DHRC, IWL & Di+: 3D foot modeling and average \\
\hline Foot reforming & IWL & Foot Reformer of scanned foot data \\
\hline Shoe design & Shoe design software suppliers & Shoe last design \\
\hline Shoe selection & Shoe maker & Shoe size selection from scan result \\
\hline Shoe customization & Shoe maker, Orthopedist & Custom shoe design \\
\hline Insole modeling & IWL, Insole design software & Insole modeler from scanned foot data \\
\hline Insole customization & Shoe maker, Orthopedist & Custom insole design \\
\hline
\end{tabular}

\section{References}

1. Martin, R. and R. Knussmann (1988) Anthropologie, Band I. Gustav Fischer, Stuttgart 